\title{
Patient satisfaction with antiretroviral therapy services and associated factors at Gondar town health centers, Northwest Ethiopia: an institution-based cross- sectional study
}

\author{
Getaneh Adissu', Gashaw Andarge Biks ${ }^{2}$ and Koku Sisay Tamirat ${ }^{3^{*}}$
}

\begin{abstract}
Background: The Human Immunodeficiency Virus (HIV) with which over 37 million peoples are living is the leading cause of morbidity and mortality worldwide. The rapid expansion of antiretroviral treatment has dramatically reduced HIV related deaths and transmissions. Patient satisfaction could be an indispensable parameter used to measure patients' desired fulfillment by the services. Hence, this study aimed to determine the level of patient satisfaction with antiretroviral therapy services and determinants at Gondar town health centers.

Methods: An institution-based cross-sectional study was conducted from November 1 to 30, 2018. The systematic random sampling technique was used to select 663 HIV/AIDS patients on antiretroviral therapy follow-ups. Data were collected using a pretested interviewer-administered questionnaire and patient medical document reviews. Summary statistics such as means, medians and proportions were calculated and presented in the form of tables, graphs, and texts. Bivariate and multivariable logistic regression analysis was fitted and adjusted odds ratio (AOR) with a 95\% confidence interval (Cl) was computed to assess the strength of association. Variables with $p$-value 0.05 at multivariable logistic regression considered significant determinants of patient satisfaction.
\end{abstract}

Results: The overall patient satisfaction with antiretroviral therapy services was $75.4 \%$ (95\% $\mathrm{Cl}, 71.9$ to $79 \%)$. Patients' age 38-47 years ( $A O R=5.90,95 \% \mathrm{Cl}: 3.38,10.31)$ and $\geq 48$ years ( $A O R=2.66,95 \% \mathrm{Cl}: 1.38,5.12)$, absence of signs and directions to ART clinic (AOR $=0.53,95 \% \mathrm{Cl}: 0.35,0.82$ ), Azezo health center ( $\mathrm{AOR}=2.68,95 \% \mathrm{Cl}: 1.47,4.66)$ and Teda health center $(A O R=4.44,95 \% \mathrm{Cl}: 1.73,11.30)$, and travel that took more than $1 \mathrm{~h}(\mathrm{AOR}=0.56 ; 95 \% \mathrm{Cl}: 0.32,0.97)$ were determinants of patient satisfaction with the services.

Conclusion: The overall patient satisfaction with antiretroviral therapy service was lower than the national target of $85 \%$ with the marked difference among health centers. Older age, absence of signs and directions to ART clinics, and longer travel from home to health centers were factors influencing patient satisfaction with antiretroviral treatments. This suggests that further improvement of accessibility is likely needed to increase patient satisfaction.

Keywords: Patient satisfaction, Antiretroviral therapy services, HIV/AIDS, Health centers

\footnotetext{
* Correspondence: kokusisay23@gmail.com

${ }^{3}$ Department of Epidemiology and Biostatistics, College of Medicine and Health Science, Institute of Public Health Science, University of Gondar, Gondar, Ethiopia

Full list of author information is available at the end of the article
}

(c) The Author(s). 2020 Open Access This article is distributed under the terms of the Creative Commons Attribution 4.0 International License (http://creativecommons.org/licenses/by/4.0/), which permits unrestricted use, distribution, and reproduction in any medium, provided you give appropriate credit to the original author(s) and the source, provide a link to the Creative Commons license, and indicate if changes were made. The Creative Commons Public Domain Dedication waiver (http://creativecommons.org/publicdomain/zero/1.0/) applies to the data made available in this article, unless otherwise stated. 


\section{Background}

Having claimed the lives of more than 20 million peoples in the last three decades, the Human Immunodeficiency Virus (HIV) is the leading cause of morbidity and mortality worldwide [1-3]. Currently, more than 36 million people the majority of whom are from Sub-Saharan countries are living with HIV/ AIDS [1, 4]. East and southern African countries share the highest burden of the disease with an estimated 19 million people, nearly $51.7 \%$ of the global burden living with it [1,3]. Globally, the provisions of HAART have shown remarkable progress by reducing HIV/AIDS-related death and new infection by 45 and $23 \%$, respectively in the last 10 years [5].

Although Ethiopia is one of the most affected highly affected Sub-Saharan countries, the national HIV prevalence dropped from 1.4 in 2005 to $0.9 \%$ in 2016 despite the regional variations ranging from 1.2 in Amhara to $4.2 \%$ in the Gambella region, Ethiopia [6]. According to a recent report, HIV/AIDS-related deaths and new infections decreased by 57 and 5\%, respectively from 2010. However, tremendous efforts are still necessary to further control HIV/AIDS spread in the community and to realize the envisioned target of 90-90-90 by the end of 2020 , given that only $79 \%$ of knew their HIV status of whom $65 \%$ of them are on ART treatment. Moreover, Ethiopia launched a five-year national HIV/AIDS strategic plan (2015-2020) based on the investment framework strategy to control HIV/AIDS [2, 7]. Although antiretroviral therapy showed a marked effect on the reduction of death, opportunistic infections, and transmission, only 21.7 million (59\%) of the estimated patients were receiving highly active antiretroviral therapy (HAART) by the end of 2017 [1, 4, 8]. In addition, safe and effective ART contributed to improved quality of life, increased survival, decreased HIV-related deaths, prevented the emergence of drug resistance, and decreased social crisis from a number of orphanages [9]. Moreover, the introduction of antiretroviral therapy transformed HIV/AIDS from its nature of high virulence to a manageable health condition.

Patient satisfaction is an indispensable health service outcome measurement which defined as the perceived fulfillment of patient needs and desires through the delivery of healthcare services [10]. It reflects providers' ability to successfully deliver care that meets patient expectations and needs. Satisfaction is a participatory measurement that helps in a better understanding of the patient-physician relationship and quality of service to the extent of patient needs fulfillment, more importantly for patients on chronic diseases such as HIV/AIDS follow up. Besides, patient satisfaction is an integral part of the health system management strategies to assess the performance of the health system for quality assurance and accreditations [11]. Patient satisfaction is evaluated from the dimensions of the health facility environment, patient-physician relationships, and service availability [12-15]. Moreover, satisfaction among HIV/AIDS patients helps in good adherence and favorable outcome of HAART such as backstage distributions, survival, and low incidence of opportunistic infections (OI) [16]. Socio-demographic characteristics (residence, educational level), clinical conditions such as presence of OI, and hygiene and sanitation of health facilities were factors that influence patient satisfaction [11, 16-19]. The Federal Democratic Republic Ministry of Health of Ethiopia launched a new initiative which required service providers to be Compassionate, Respectful and Caring (CRC) in order to improve patient-physician relationship and increase patient satisfaction from health care services [20]. In addition, optimized and sustained quality of care and treatment are the objectives of the five-year HIV/AIDS strategic plan Ethiopia, which aimed to improve patient satisfaction with HAART services at the health facilities. Most patient satisfaction assessments done among health facilities of Ethiopia were from the perspectives of general services. To date, there have been no patient satisfaction assessments in the health centers which are the components of primary health care units in the Ethiopia health system.

Therefore, this study aimed to assess the level of patient satisfaction with antiretroviral therapy services and it's determinants at Gondar town health facilities. This study could evaluate the progress of quality service provision to HIV/AIDS patients. In addition, this study could help to increase the decentralization of services by minimizing perceived gaps between patient service needs and the delivery. Furthermore, it might assist in the planning and development of patient satisfaction related to quality improvement projects in ART services at the health center level.

\section{Methods \\ Study design, period and setting}

An institution-based cross-sectional study was conducted on four health centers in Gondar town from November 1 to 30,2018 . The town is located in northwest Ethiopia $740 \mathrm{~km}$ from the capital Addis Ababa. It has eight public health centers and one comprehensive specialized hospital. Four of the health centers provide antiretroviral therapy services to more than 3000 HIV/AIDS patients in the town and nearby districts. Each health center had a separate ART clinic with its own pharmacy and laboratory units specifically designed to serve only HIV infected patients enrolled for antiretroviral treatment. In addition, each unit has adherence and psychosocial support staff assigned to improve adherence and disclosure. 


\section{Source and eligible population}

All adult HIV/AIDS patients who had antiretroviral treatment follow-ups at Gondar health centers were the source population. Similarly, all adult HIV positive people who were on antiretroviral treatment follow-ups for at least 6 months and available during data collection were eligible to take part in the study. Patients who were severely ill and had mental disorders were excluded.

\section{Sample size determination and sampling procedure}

The sample size was determined by using the single population proportion with the assumptions of $80 \%$ power, $4 \%$ margin of error and $41.5 \%$ proportion of satisfaction among HIV/AIDS patients from a study done in Nigeria [21], by considering a $10 \%$ non-response rate. The final sample was 663 adult HIV/AIDS patients who were on ART at least for 6 months. Following the opening of HIV/AIDS care and treatment, Gondar, Azezo, Maraki, and Teda health centers enrolled 2160, 768, 381 and 295 ART clients, respectively. The sample was proportionally assigned to each health center based on the number of patients on follow-ups. Accordingly, 398, 141, 70 and 54 ART clinic visitors were systematically selected from Gondar, Azezo, Maraki and Teda health centers, respectively.

\section{Data collection procedures}

Data were collected through a face-to-face intervieweradministered structured questionnaire and document reviews. The questionnaire was initially developed in English after reviewing relevant literature and translated into the local language (Amharic) and back into English to ensure consistency. The questionnaire contained sociodemographic, clinical characteristics and satisfaction measurement domains. The structured questionnaire was pre-tested on $5 \%$ of the total sample in a similar setup out of the study area to assure the validity and consistency of the tool. Training was given to four data collectors and two supervisors on how to interview patients using a structured questionnaire and to check the completeness of the questionnaire during interviews. Data about the station and some socio-demographic characteristics such as age and distance travel collected through interview, whereas clinical characteristics like ART regimen they took, recent viral load and opportunistic infections were harvested from patient medical charts and databases. A data collector checked the completeness of each questionnaire at the end of each interview.

\section{Measurements and operational definitions}

In this work, we used 20 questions of the five-point Likert scale, which had domains like the health center physical environment, health care workers' communication and relationship, accessibility and availability of services to assess patient satisfaction. In the Likert scale rating, 1, 2, 3, 4 and 5 were given for "very dissatisfied", "dissatisfied", "neutral", "satisfied", and "very satisfied", respectively. These 20 satisfaction measurement items are scales used to assess the level of satisfaction with antiretroviral therapy services provided in the ART clinics of the town. Since there is no standardized satisfaction measurement tool, we adopt it from previous studies and general services reform measurement perspectives. The Cronbach's alpha test was used to assess the internal consistency of the satisfaction measurement tool which turned out to be $86 \%$.

Patient satisfaction with antiretroviral therapy services is the response variable, whereas socio-demographic characteristics (age, sex, residence, level of education, religion, occupation, and monthly income), clinical conditions (duration on antiretroviral therapy, recent viral load, ART regimen, adherence status and presence of OI during visits), and physical environment of health center (availability of signs and directions to ART clinic, availability of prescribed ancillary drugs, distance of health facility from living area of the patient and study health center) were the independent variables.

Satisfaction: the degree of concordance between patient expectations of ideal care and their perceptions of real care received.

Satisfied: patient who scored above $60 \%$ on the satisfaction measuring items [22].

Dissatisfied: patients who scored $60 \%$ and below among the satisfaction measuring items [22].

Opportunistic infection: An infection caused by pathogens like bacteria, viruses, fungi or protozoa that take advantage of low immunity status not normally available.

Good drug adherent: if the average adherence was equal to or greater than ( $95 \%$ or $<3$ doses per month) [23].

Fair drug adherent: (85-94\% or 4-8 doses missed per month) [23].

Poor drug adherent: (less than $85 \%$ or $>9$ doses missed per month) [23].

\section{Data management, processing, and analysis}

The completed questionnaire was checked for completeness, consistency and then cleaned and coded by the principal investigator. Data entry was done using EPI data version 3.1 and exported to STATA 14 software for further analysis. Summary statistics like means, medians, and proportions were computed and tables and graphs were used to present them. The five-point Likert scales used to measure patient satisfaction were summarized and ranged between a minimum of 20 and a maximum of 100. Assumptions of normality were checked and the distribution was not normal. We dichotomized the level of satisfaction into two as "satisfied" and "dissatisfied" with a median cutoff point of 60 . A binary logistic regression model was fitted to identify factors influencing 
patient satisfaction with antiretroviral therapy services. Crude and adjusted odds ratios with a 95\% CI were computed to assess the strength of associations between independent variables and patient satisfaction. Variables with less than $0.05 p$-values in multivariable logistic regression analysis were considered as statistically significant associations.

\section{Result}

\section{Socio-demographic characteristics}

A total of 663 adult HIV/AIDS patients were included in the study with the response rate of $100 \%$. The majority $(60 \%)$ of the participants were from the Gondar health center, followed by $21.3 \%$ from Azezo, and the remaining 10.6 and $8.1 \%$ from Maraki and Teda health centers, respectively. The mean (SD) age of participants was $37.8( \pm 9.8)$ years; more than half $(54 \%)$ were aged below 37 years, with females accounting for $70.1 \%$. Most (88.1\%) of the participants were Orthodox Christians, 93.1\% were urban dwellers and only $42.7 \%$ were married. Nearly one third (31.4\%) were daily laborers (Table 1). Regarding the health center environment, $50.2 \%$ of patients saw signs and directions to ART clinics and most (87.5\%) of them traveled less than 1 hour to get ART services. Three hundred thirty-three (52\%) patients got prescribed ancillary drugs for opportunistic infections medications at pharmacies (Table 1).

\section{Clinical characteristics of patients}

The mean (SD) duration in which HIV/AIDS patients received ART was $70.4( \pm 42)$ months; about $54.45 \%$ of the patients were on ART for more than 61 months; half (51.6\%) of the patients received TDF/3TC/EFV antiretroviral treatment regimen; most $(95.6 \%)$ of them had

Table 1 Socio-demographic characteristics of respondents on patient satisfaction and associated factors towards antiretroviral therapy service at Gondar town health center, northwest Ethiopia, $2018(n=663)$

\begin{tabular}{|c|c|c|c|}
\hline Characteristics & Category & Frequency & Percentage \\
\hline \multirow[t]{3}{*}{ Age group } & $<=37$ & 358 & 54 \\
\hline & $38-47$ & 204 & 30.77 \\
\hline & $>=48$ & 101 & 15.23 \\
\hline \multirow[t]{2}{*}{ Sex } & Male & 198 & 29.9 \\
\hline & Female & 465 & 70.1 \\
\hline \multirow[t]{4}{*}{ Marital status } & Single & 81 & 12.2 \\
\hline & Married & 283 & 42.7 \\
\hline & Divorced & 205 & 30.9 \\
\hline & Widowed & 94 & 14.2 \\
\hline \multirow[t]{3}{*}{ Level of education } & No formal education & 335 & 50.6 \\
\hline & Primary and secondary school & 274 & 41.3 \\
\hline & College and above & 54 & 8.1 \\
\hline \multirow[t]{2}{*}{ Residence } & Urban & 617 & 93.1 \\
\hline & Rural & 47 & 6.9 \\
\hline \multirow[t]{4}{*}{ Religion } & Orthodox & 584 & 88.1 \\
\hline & Muslim & 61 & 9.2 \\
\hline & Protestant & 11 & 1.7 \\
\hline & Others & 7 & 1.1 \\
\hline \multirow[t]{6}{*}{ Occupation } & Student & 21 & 3.1 \\
\hline & Government employee & 92 & 13.9 \\
\hline & Private worker & 132 & 19.9 \\
\hline & Daily labor & 208 & 31.4 \\
\hline & Merchant & 85 & 12.8 \\
\hline & Housewife & 125 & 18.9 \\
\hline \multirow[t]{4}{*}{ Monthly income (ETB) } & No income & 24 & 3.6 \\
\hline & $<=1200$ & 322 & 48.6 \\
\hline & $1201-2400$ & 197 & 29.7 \\
\hline & $>=2401$ & 120 & 18.1 \\
\hline
\end{tabular}


recent viral load measurement of below 1000 copies $/ \mathrm{ml}$. About one fourth (25.3\%) of the patients had opportunistic infections during the data collection. Four hundred nine $(61.7 \%)$ of the respondents had good adherence status (Table 2).

\section{Patient satisfaction with antiretroviral therapy (ART) services}

This study revealed that the overall patient satisfaction with antiretroviral service was $75.4 \%$ with a $95 \%$ CI: 71.9-79). The overall satisfaction specific to each health center ranged from 71.4 to $88.9 \%$. Generally, most of the 'response was highly $(97.1 \%)$ satisfied with the convenience of time to get ART services and (91.5\%) convenience situations and (90.8\%) with easy accessibility of drugs at pharmacies. On the other hand, (40.7\%) of the patients showed low satisfaction with the availability and accessibility of latrines and (27.3\%) with the cleanness and comfortability of latrines at the health centers. Detail patient satisfaction measurements mentioned in (Table 3).

\section{Factors affecting patient satisfaction on antiretroviral therapy service}

For patients who are aged between 38 to 47 years or above 48 years, the odds of satisfaction were $5.9(\mathrm{AOR}=$ $5.90 ; 95 \% \mathrm{CI}: 3.38-10.31)$ and $2.66(\mathrm{AOR}=2.66 ; 95 \% \mathrm{CI}$ : 1.38-5.12) times higher, respectively, compared to those aged below 37 years. For patients who traveled more than $1 \mathrm{~h}$ to get services, the odds of satisfaction was

Table 2 Clinical Characteristics of respondents on patient satisfaction and associated factors towards antiretroviral therapy services at Gondar Town Health Center, Northwest Ethiopia, $2018(n=663)$

\begin{tabular}{llll}
\hline Variables & Category & Frequency & Percentage \\
\hline Duration on ART & $\leq 60$ Months & 302 & 45.55 \\
& $>60$ Months & 361 & 54.45 \\
Recent viral load & $<1000 \mathrm{copy} / \mathrm{ml}$ & 634 & 95.6 \\
& $>=1000 \mathrm{copy} / \mathrm{ml}$ & 29 & 4.4 \\
Adherence status & Good & 409 & 61.7 \\
& Fair & 158 & 23.8 \\
Opportunistic infections & Poor & 96 & 14.5 \\
& Yes & 168 & 25.3 \\
ART regimen & No & 495 & 74.7 \\
& AZT/3TC/NEV & 120 & 18.1 \\
& TDF/3TC/EFA & 342 & 51.6 \\
& AZT/3TC/EFA & 100 & 15.1 \\
& TDF/3TC/NEV & 101 & 15.2 \\
\hline
\end{tabular}

AZT/3TC/NEV: Zidovudine/Lamivudine/Neverapin TDF/3TC/EFV: Tenofovir/ Lamivudine/Efavirenz. AZT/3TC/EFA: Zidovudine/Lamivudine/ Enfavirez TDF/3TC/NEV: Tenofovir/ Lamivudine/ Efavirenz. decreased by $44 \%$ compared to those who traveled less $(\mathrm{AOR}=0.56 ; 95 \% \mathrm{CI}: 0.32,0.97)$. For those who did not notice signs and directions to antiretroviral therapy clinics, the odds of satisfaction dropped by $47 \%$ compared to those who saw signs and directions to service units (AOR $=0.53 ; 95 \%$ CI:0.35,0.82). Compared to patients who had to follow-ups at the Gondar health center, the odds of satisfaction at Azezo and Teda health centers were $2.62(\mathrm{AOR}=2.68 ; 95 \% \mathrm{CI}: 1.472 .48)$ and $4.44 \quad(\mathrm{AOR}=4.4 ; 95 \% \mathrm{CI}: 1.73,11.30)$ times higher (Table 4).

\section{Discussion}

The overall patient satisfaction, which included significant variations ranging from 71.4 to $88.9 \%$ among health centers, was $75.4 \%$ in Gondar. Age of respondents, absence of signs and directions to ART clinic, and longer travel from home to health centers were factors influencing patient satisfaction with ART services. Significant variations among health centers might be explained by differences in the setups, health professional experiences, and materials availability, and accessibility in the health centers. The level of satisfaction in this study was consistent with that of a study at a referral hospital in Ethiopia (75.2\%) [14] and a public hospital in Nigeria (71.4\%) [21]. Patients satisfaction measurement had important implications for services providers and planners to identify gaps and improvement of service quality of the health care system.

However, this finding was lower than results of health centers in Tigray region, Ethiopia (89.6\%) [22], Addis Ababa public hospitals (85.5\%) [24], Sidama hospital, southern Ethiopia (85.5\%) [15], and Bamenda-Cameroon 91.2\% [19]. The reason could be the differences in the study setting, socio-demographic characteristics, and service units. In addition studies in Addis Ababa and Sidama hospitals, patients satisfaction measurement was focused on laboratory services. Furthermore, hospitals had better diagnostic and medical personnel for better health care service provision which fulfills patient expectations compared to health centers.

On the other hand, this study finding was also higher compared to the result at the University of Gondar hospital which assessed satisfaction with ART laboratory services $(54.7 \%)$ and Tanzania $(65.2 \%)$ [12, 25]. The possible explanations might be differences in study settings, quality of service and units assessed for satisfaction such as laboratories. A study done in Tanzania included private health facilities which might have affected the level of satisfaction.

As shown in Table 3, among domains used to assess satisfaction, the convenience of time to get services and easy accessibility of pharmacies attracted high satisfaction scores, In contrast, domains related to health center 
Table 3 Rate of patients satisfaction on ART service by different measuring items in Gondar Town ART Health Centers, North wet Ethiopia,2018 $(n=663)$

\begin{tabular}{|c|c|c|c|c|c|c|c|}
\hline S.N & Variables & $\begin{array}{l}\text { V. dissatisfied } \\
\text { No }(\%)\end{array}$ & $\begin{array}{l}\text { dissatisfied } \\
\text { No (\%) }\end{array}$ & $\begin{array}{l}\text { Neutral } \\
\text { No (\%) }\end{array}$ & $\begin{array}{l}\text { satisfied } \\
\text { No (\%) }\end{array}$ & $\begin{array}{l}\text { v. satisfied } \\
\text { No (\%) }\end{array}$ & $\begin{array}{l}\text { Mean (SD) } \\
\text { rating }\end{array}$ \\
\hline 1 & Staff treats all patients fairly and equally & $96(14.5)$ & $79(11.9)$ & $67(10.1)$ & $375(56.6)$ & $46(7.1)$ & $3.29( \pm 1.20)$ \\
\hline 2 & Health professional compassion and support the patient & $22(3.3)$ & $67(10.1)$ & $61(9.2)$ & $462(69.7)$ & $51(7.7)$ & $3.68( \pm 0.87)$ \\
\hline 3 & ART clinic staffs availability on working hours & $130(19.6)$ & $86(13)$ & $21(3.2)$ & $393(59.3)$ & $33(5)$ & $3.17( \pm 1.29)$ \\
\hline 4 & Privacy during examination & $14(2.1)$ & $31(4.7)$ & $96(14.5)$ & $454(68.5)$ & $68(10.3)$ & $3.80( \pm 0.76)$ \\
\hline 5 & Health professional respect the patient and courtesy & $39(5.9)$ & $58(8.7)$ & $46(6.9)$ & $454(68.5)$ & $66(10)$ & $3.67( \pm 0.97)$ \\
\hline 6 & Health professional obligate and adoration ethics & $43(6.5)$ & $61(9.2)$ & $50(7.5)$ & $457(68.9)$ & $52(7.8)$ & $3.62( \pm 0.98)$ \\
\hline 7 & Cleanness of health center and rooms & $56(8.4)$ & $126(19)$ & $73(11)$ & $377(56.9)$ & $31(4.7)$ & $3.30( \pm 1.09)$ \\
\hline 8 & Comfort ability of seating chair & $68(10.3)$ & $153(23.1)$ & $66(10)$ & $353(53.2)$ & $23(3.5)$ & $3.16( \pm 1.13)$ \\
\hline 9 & Comfort ability of waiting and examination room & $63(9.5)$ & $133(20.1)$ & $112(16.9)$ & $351(52.9)$ & $4(0.6)$ & $3.15( \pm 1.05)$ \\
\hline 10 & Availability and accessibility of latrine & $116(17.5)$ & $202(30.5)$ & $75(11.3)$ & $266(40.1)$ & $4(0.6)$ & $2.75( \pm 1.17)$ \\
\hline 11 & Cleanness and comfort ability of latrine & $201(30.3)$ & $187(28.2)$ & $94(14.2)$ & $177(26.7)$ & $4(0.6)$ & $2.39( \pm 1.19)$ \\
\hline 12 & Drug available during visit & $29(4.4)$ & $78(11.8)$ & $13(2)$ & $448(67.6)$ & $95(14.3)$ & $3.75( \pm 0.98)$ \\
\hline 13 & Laboratory tests available during the visit & $71(10.7)$ & $107(16.1)$ & $23(3.5)$ & $380(57.3)$ & $82(12.4)$ & $3.44( \pm 1.20)$ \\
\hline 14 & Sufficiency of service giving rooms & $39(5.9)$ & $92(13.9)$ & $47(7.1)$ & $438(66.1)$ & $47(7.1)$ & $3.54( \pm(1.01)$ \\
\hline 15 & Availability of good diagnosis & $61(9.2)$ & $44(6.6)$ & $28(4.2)$ & $449(67.7)$ & $81(12.2)$ & $3.67( \pm 1.07)$ \\
\hline 16 & Easily obtaining drugs at pharmacies during visiting & $23(3.5)$ & $21(3.2)$ & $17(2.6)$ & $502(75.7)$ & $100(15.1)$ & $3.95( \pm 0.78)$ \\
\hline 17 & Convenient situations to get drugs from pharmacy & $6(0.9)$ & $39(5.9)$ & $11(1.7)$ & $509(76.8)$ & $98(14.8)$ & $3.98( \pm 0.69)$ \\
\hline 18 & Convince and safety of ART clinic for visiting & $58(8.7)$ & $83(12.5)$ & $23(3.5)$ & $445(67.1)$ & $54(8.1)$ & $3.53( \pm 1.09)$ \\
\hline 19 & Distance of Health center from leaving area & $32(4.8)$ & $25(3.8)$ & $48(7.2)$ & $491(74.1)$ & $67(10.1)$ & $3.80( \pm 0.85)$ \\
\hline 20 & Convenience of time to get ART services & $4(0.6)$ & $5(0.8)$ & $10(1.5)$ & $587(88.5)$ & $57(8.6)$ & $4.03(0.42)$ \\
\hline \multicolumn{2}{|r|}{ Overall level of satisfaction by health centers (satisfaction $>60$ ) } & & & \multicolumn{2}{|c|}{ Satisfied n (\%) } & \multicolumn{2}{|c|}{ Mean (SD) rating } \\
\hline 1 & \multicolumn{2}{|l|}{ Gondar health center } & & \multicolumn{2}{|l|}{$284(71.4)$} & \multicolumn{2}{|l|}{$3.43( \pm 0.56)$} \\
\hline 2 & \multicolumn{2}{|l|}{ Maraki health center } & & \multicolumn{2}{|l|}{$50(71.4)$} & \multicolumn{2}{|l|}{$3.53( \pm 0.77)$} \\
\hline 3 & \multicolumn{2}{|l|}{ Azezo health center } & & \multicolumn{2}{|l|}{$118(83.7)$} & \multicolumn{2}{|l|}{$5.59( \pm 0.49)$} \\
\hline 4 & \multicolumn{3}{|l|}{ Teda health center } & \multicolumn{2}{|l|}{$48(88.9)$} & \multicolumn{2}{|l|}{$3.59( \pm 0.48)$} \\
\hline
\end{tabular}

physical environment such as availability, accessibility and cleanness, and comfort of latrines received lower ratings. This could be due to the fact that poor environmental hygiene in health facilities is associated with increased occurrence of nosocomial infections which might affect the safety of immunocompromised patients. This finding showed that higher satisfaction $(97.1 \%)$ was reported on the convenience of time to get services, the convenience of situations to get drugs from pharmacies (91.5\%) and distance of health center from living area $84.2 \%$. These findings were consistent with those of other studies conducted at government hospitals of eastern Ethiopia [26].

This study showed that patients who were older than 38 years were associated with increased satisfaction with antiretroviral treatment services compared to younger ones. This was incongruent with results in Ethiopia and Nigeria. HIV/AIDS is a stigmatizing disease that affects social interactions; thus, older patients are psychologically stable and more satisfied with services provided at health centers $[14,17,27]$.

For patients who traveled more than $1 \mathrm{~h}$ from home to health centers, satisfaction decreased by $44 \%$ compared to those patients who traveled less than $1 \mathrm{~h}$ to get to antiretroviral therapy service health centers. This result was consistent with those of studies in the Tigray region and the public health facility of the Sidama zone of Ethiopia [16, 22]. The possible explanations might be the fact that long-distance travel is often associated with increased financial expenditure and absence from work and school.

Patients who did not observe signs and directions to antiretroviral therapy units were associated with lower rates of patient satisfaction compared to those who observed signs and directions. This finding was consistent with that of a previous study in Ethiopia. The possible reason for the decreased satisfaction could be that directions to ART clinics help patients to get where ART 
Table 4 Bi-variable and multivariate analysis of predictors to assess factors affecting patient satisfaction on antiretroviral therapy services at Gondar town health centers, northwest Ethiopia,2018( $n=663)$

\begin{tabular}{|c|c|c|c|c|}
\hline \multirow[t]{2}{*}{ Variables } & \multicolumn{2}{|c|}{ Patient satisfied } & \multirow{2}{*}{$\begin{array}{l}\text { Crude } \\
\text { OR(95\%Cl) }\end{array}$} & \multirow{2}{*}{$\begin{array}{l}\text { Adjusted } \\
\text { OR(95\%Cl) }\end{array}$} \\
\hline & Yes & No & & \\
\hline \multicolumn{5}{|l|}{ Age category } \\
\hline$<=37$ & 228 & 130 & 1 & 1 \\
\hline $38-47$ & 186 & 18 & $5.89(3.46,10.00)$ & $5.90(3.38,10.31)^{*}$ \\
\hline$>=48$ & 86 & 15 & $3.26(1.81,5.89)$ & $2.66(1.38,5.12)^{*}$ \\
\hline \multicolumn{5}{|l|}{ Sex } \\
\hline Male & 156 & 42 & 1 & 1 \\
\hline Female & 344 & 121 & $0.76(0.51-1.14)$ & $0.76(0.51,1.14)$ \\
\hline \multicolumn{5}{|l|}{ Marital status } \\
\hline Single & 54 & 27 & 1 & 1 \\
\hline Married & 209 & 74 & $1.41(0.82-2.40)$ & $1.04(0.57,1.88)$ \\
\hline Divorced & 159 & 46 & $1.73(0.98-3.04)$ & $1.34(0.71,2.53)$ \\
\hline Widowed & 78 & 16 & $2.43(1.21-4.90)$ & $1.52(0.66,3.48)$ \\
\hline \multicolumn{5}{|l|}{ Educational status } \\
\hline No formal education & 259 & 76 & 1 & 1 \\
\hline Primary and secondary school & 199 & 75 & $0.77(0.53-1.12)$ & $0.76(0.51,1.15)$ \\
\hline Collage and above & 42 & 12 & $1.02(0.51-2.04)$ & $0.88(0.41,1.91)$ \\
\hline \multicolumn{5}{|l|}{ Duration on ART } \\
\hline$\leq 60$ months & 220 & 82 & 1 & 1 \\
\hline$\geq 61$ months & 280 & 81 & $1.28(0.90-1.83)$ & $1.03(0.69-1.53)$ \\
\hline \multicolumn{5}{|l|}{ Adherence status } \\
\hline Good & 313 & 96 & 1 & 1 \\
\hline Fair & 121 & 37 & $1.00(0.65-1.54)$ & $0.92(0.57,1.48)$ \\
\hline Poor & 66 & 30 & $0.67(0.41-1.10)$ & $0.84(0.48,1.46)$ \\
\hline \multicolumn{5}{|c|}{ Availability of signs and directions to the ART clinic } \\
\hline Yes & 258 & 75 & 1 & 1 \\
\hline No & 242 & 88 & $0.79(0.56-1.13)$ & $0.53(0.35,0.82)^{*}$ \\
\hline \multicolumn{5}{|c|}{ Distance travel from home to health centers } \\
\hline$\leq 1 \mathrm{~h}$ & 446 & 134 & 1 & 1 \\
\hline$>1 \mathrm{~h}$ & 54 & 29 & $0.55(0.34-0.91)$ & $0.56(0.32,0.97)^{*}$ \\
\hline \multicolumn{5}{|l|}{ Study health centers } \\
\hline Gondar Health Center & 284 & 114 & 1 & 1 \\
\hline Maraki Health Center & 50 & 20 & 1.04(0.57-1.76) & $1.27(0.67,2.43)$ \\
\hline Azezo Health Center & 118 & 23 & $2.05(1.25-3.380$ & $2.68(1.47,4.66)^{*}$ \\
\hline Teda Health Center & 48 & 6 & $3.21(1.33-7.71)$ & $4.44(1.73,11.30)^{*}$ \\
\hline
\end{tabular}

* Statistical significant at a $p$-value of 0.05, ART Antiretroviral Treatment

clinics are located. That is because patients fear the stigma and discrimination to ask other people to show them where the ART clinic is found [13].

This study has implications for patients, health care workers, public health experts and health system administrators for the improvement of health services quality and increasing patient retention on the HAART. In addition, factors identified like distance travel and sign and direction of health facilities suggest the need to scale up of health service accessibility and availability through further decentralization of services [28].

Although this study used a large sample size and multi-center approach, it has limitations related to the lack of the qualitative component which is important for assessing patient insight and beliefs. Besides the satisfaction measurement tool which is not standardized and 
might introduce misclassifications and bias. Moreover, this study result may not show the satisfaction of patients who had follow-ups in hospitals. Finally, the dichotomization of Likert scale measurements might introduce misclassification and disruption of the data nature.

\section{Conclusion}

The overall patient satisfaction with antiretroviral therapy service was lower than the national target of $85 \%$ with the marked difference among health centers. Older age, absence of signs and directions to ART clinics, and longer travel from home to health centers were factors influencing patient satisfaction with antiretroviral treatments. The findings strongly suggest that programmatic/ health policy decisions related to increased access to ART in the region. This suggests that further improvement of accessibility is mandatory for increasing patient satisfaction.

\section{Abbreviations}

AIDS: Acquired Immune deficiency Syndrome; AOR: Adjusted Odds Ratio; ART: Antiretroviral Therapy; Cl: Confidence Interval; CRC: Compassionate Respectful and Caring; FMOH: Federal Ministry of Health; HAART: Highly Active Antiretroviral Therapy; HC: Health Center; HIV: Human Immunodeficiency Virus; Ol: Opportunistic Infection; SD: Standard deviation

\section{Acknowledgments}

We would like to thank data collators, supervisors and study participants for their contributions made.

\section{Authors' contributions}

GA, GAB, and KST conceived the study, involved in the study design, data analysis, drafted the manuscript and critically reviewed the manuscript. All authors read and approved the final manuscript.

\section{Funding}

I did not receive external funding for this research.

\section{Availability of data and materials}

The datasets used during the current study are available from the corresponding author on a reasonable request.

\section{Ethics approval and consent to participate}

Ethical clearance was obtained from the Instructional review board of the University of Gondar department of an institution of public health. Permission letter had been received from Gondar city administration zonal health department and health center head. Verbal consent was taken from each study participant before data collection started. Verbal consent was used because of low literacy level in the community as well as some participants are uncomfortable to sign the forms. Confidentiality was kept by making interview in separate place and of any information provided during data collection procedure were anonymous.

\section{Consent for publication}

Not applicable as there is no image or other confidentiality related issues.

\section{Competing interests}

The authors declare that they have no competing interests.

\section{Author details}

${ }^{1}$ Federal Democratic Republic of Ethiopia, Pharmaceuticals Fund and Supply Agency, Addis Ababa, Ethiopia. ${ }^{2}$ Department of Health System and Policy, College of Medicine and Health Science, Institute of Public Health, University of Gondar, Gondar, Ethiopia. ${ }^{3}$ Department of Epidemiology and Biostatistics,
College of Medicine and Health Science, Institute of Public Health Science, University of Gondar, Gondar, Ethiopia.

Received: 3 July 2019 Accepted: 27 January 2020

Published online: 06 February 2020

\section{References}

1. HIV/AIDS. J.U.N.P.o., Global AIDS update. Geneva: UNAIDS; 2016. p. 2016

2. office (HPCO). F.H.A.p.a.c., Country progress report on the HIV response. Plan, Monitoring and Evaluation Directorate. Addis Ababa: Federal Democratic Republic of Ethiopia; 2014.

3. World Health Organization. World health statistics 2015. Geneva: World Health Organization; 2015.

4. Sidibé M, Loures L, Samb B. The UNAIDS 90-90-90 target: a clear choice for ending AIDS and for sustainable health and development. J Int AIDS Soc. 2016;19(1):21133.

5. HIV/AIDS, U.N.P.o., UNAIDS data 2017. 2018, Recuperado de: http://www. unaids.org/sites/default/files/media_asset ....

6. Central Statistical Agency (CSA) [Ethiopia] and ICF. Ethiopia demographic and health survey 2016: HIV Report [Ethiopia]. Addis Ababa, Ethiopia, and Rockville, Maryland, USA: CSA and ICF; 2016.

7. Organization, W.H. Consolidated guidelines on HIV prevention, diagnosis, treatment and care for key populations-2016 update. Geneva: World Health Organization; 2016.

8. Bekker L-G, et al. Advancing global health and strengthening the HIV response in the era of the sustainable development goals: the international AIDS society-lancet commission. Lancet. 2018;392(10144):312-58.

9. Motilewa $\mathrm{O}$, et al. A comparative study of health related quality of life among HIV patients on pre HAART and HAART in Uyo south South Nigeria. J Antivir Antiretrovir. 2015:7:60-8.

10. Hudak PL, Hogg-Johnson S, Bombardier C, McKeever PD, Wright JG. Testing a new theory of patient satisfaction with treatment outcome. Medical care. 2004. p. 726-39.

11. Assefa F, Mosse A. Assessment of clients' satisfaction with health service deliveries at Jimma university specialized hospital. Ethiop J Health Sci. 2011; 21(2):101-10.

12. Abebe TB, et al. expectation and satisfaction of hiV/AiDs patients toward the pharmaceutical care provided at gondar University referral hospital, northwestern ethiopia: a cross-sectional study. Patient preference and adherence. 2016;10:2073.

13. Ambelie YA, Demssie AF, Gebregziabher MG. Patients' satisfaction and associated factors among private wing patients at Bahirdar Felege Hiwot referral hospital, North West Ethiopia. J Public Health. 2014;2:417-23.

14. Atsebeha KG, Chercos DH. High antiretroviral therapy service delivery satisfaction and its' associated factors at Midre-genet hospital; Northwest Tigray, Ethiopia. BMC Health Serv Res. 2018;18(1):223.

15. Belay $M$, et al. HIV/ AIDS patients' satisfaction on ART laboratory service in selected governmental hospitals, Sidamma zone, southern Ethiopia. Sci J Public Health. 2013;1:85.

16. Nezenega ZS, Tafere TE. Patient satisfaction on tuberculosis treatment service and adherence to treatment in public health facilities of Sidama zone, South Ethiopia. BMC Health Serv Res. 2013;13(1):110.

17. Bekele $A$, et al. Levels of outpatient satisfaction at selected health facilities in six regions of Ethiopia. Ethiop J Health Dev. 2008;22(1):42-8.

18. Mindaye T, Taye B. Patient's satisfaction with laboratory services at antiretroviral therapy clinics in public hospitals, Addis Ababa, Ethiopia. BMC research notes. 2012;5(1):1-7.

19. Wung BA, Peter NF, Atashili J. Clients' satisfaction with HIV treatment services in Bamenda, Cameroon: a cross-sectional study. BMC Health Serv Res. 2016;16(1):280.

20. Berhe $\mathrm{H}$, et al. Status of caring, respectful and compassionate health care practice in Tigrai regional state: patients' perspective. Int J. 2017; 10(3):1118.

21. Umeokonkwo CD, et al. Patients' satisfaction with HIV and AIDS care in Anambra state, Nigeria. PloS one. 2018;13(10):e0206499.

22. Tessema SB, Adane MM. Assessment of antiretroviral treatment (ART) care service provision in Tigray region health centers, North Ethiopia. BMC Health Serv Res. 2015;15(1):368.

23. Tiyou A, et al. Predictors of adherence to antiretroviral therapy among people living with HIV/AIDS in resource-limited setting of Southwest Ethiopia. AIDS Res Ther. 2010;7(1):39. 
24. Mindaye T, Taye B. Patients satisfaction with laboratory services at antiretroviral therapy clinics in public hospitals, Addis Ababa, Ethiopia. BMC research notes. 2012;5(1):184.

25. Mfinanga S, et al. Patient's dissatisfaction with the public and private laboratory services in conducting HIV related testing in Tanzania. BMC Health Serv Res. 2008;8(1):167.

26. Teklemariam Z, et al. Clients and clinician satisfaction with laboratory services at selected government hospitals in eastern Ethiopia. BMC research notes. 2013;6(1):15.

27. Oljira L, Gebre-Selassie S. Satisfaction with outpatient health services at Jimma hospital, south West Ethiopia. Ethiop J Health Dev. 2001;15(3):179-84.

28. Tran BX, Nguyen NPT. Patient satisfaction with HIV/AIDS care and treatment in the decentralization of services delivery in Vietnam. PLoS One. 2012;7(10): e46680

\section{Publisher's Note}

Springer Nature remains neutral with regard to jurisdictional claims in published maps and institutional affiliations.

Ready to submit your research? Choose BMC and benefit from:

- fast, convenient online submission

- thorough peer review by experienced researchers in your field

- rapid publication on acceptance

- support for research data, including large and complex data types

- gold Open Access which fosters wider collaboration and increased citations

- maximum visibility for your research: over $100 \mathrm{M}$ website views per year

At BMC, research is always in progress.

Learn more biomedcentral.com/submissions 